\title{
PENGEMBANGAN SISTEM TES DIAGNOSTIK KESULITAN BELAJAR KOMPETENSI DASAR KEJURUAN SISWA SMK
}

\author{
1) Samsul Hadi, ${ }^{2} \mathrm{~K}$. Ima Ismara, ${ }^{3}$ Effendie Tanumihardja \\ 1,2,3) Fakultas Teknik UNY, \\ 1)samsul_hd@uny.ac.id, 2)imaismara@uny.ac.id, 3)effendie_t@uny.ac.id
}

\begin{abstract}
Abstrak
Penelitian ini bertujuan untuk: (a) mengembangkan sistem tes diagnostik kesulitan belajar kompetensi dasar kejuruan, dan (b) mengetahui kinerja sistem tes diagnostik kesulitan belajar kompetensi dasar kejuruan siswa SMK yang dikembangkan. Penelitian ini merupakan penelitian tahun kedua dari tiga tahun yang direncanakan. Penelitian ini menggunakan pendekatan Research and Development perangkat lunak. Model pengembangan yang digunakan dalam penelitian ini adalah model modifikasi linear sequential yang disebut juga sebagai classic life cycle atau model waterfall yang memiliki 4 langkah. Analisis kebutuhan sistem dan perancangan sistem telah dilakukan pada tahun pertama. Implementasi dan validasi program dilakukan pada tahun kedua. Validasi sistem dilakukan dengan angket yang diberikan kepada 35 guru SMK untuk melihat aspek kinerja, rancangan, dan adaptabilitas sistem. Analisis data validasi dilakukan dengan statistik deskriptif. Langkah terakhir, evaluasi pemanfaatan sistem, akan dilaksanakan pada tahun ketiga. Sistem tes diagnostik kesulitan belajar kompetensi dasar kejuruan siswa SMK telah dikembangkan dengan arsitektur web client-server menggunakan bahasa pemrograman PHP, HTML, dan Java dengan perangkat lunak pendukung web server Apache, MySQL, dan web browser Chrome. Sistem ini memiliki tiga kelompok pengguna, yaitu admin, guru, dan siswa. Hasil analisis aspek kinerja, rancangan, dan adaptabilitas sistem secara keseluruhan mempunyai rata-rata penilaian sebesar 3.57 dari skala 1-4, sehingga termasuk kategori sangat baik. Karena itu sistem yang telah dikembangkan dapat digunakan pada penelitian lebih lanjut pada tahun ketiga, yaitu evaluasi pemanfaatan sistem.
\end{abstract}

Kata kunci: kompetensi dasar kejuruan, tes diagnostik.

\section{DEVELOPING DIAGNOSTIC TEST SYSTEM OF LEARNING DIFFICULTY OF BASIC VOCATIONAL COMPETENCE OF STUDENTS OF VOCATIONAL HIGH SCHOOLS}

\author{
1) Samsul Hadi, ${ }^{2} \mathrm{~K}$. Ima Ismara, ${ }^{3}$ Effendie Tanumihardja \\ 1,2,3) Fakultas Teknik UNY, \\ 1)samsul_hd@uny.ac.id, 2)imaismara@uny.ac.id, 3)effendie_t@uny.ac.id
}

Abstract

This research aimed to: (a) develop a diagnostic test system of basic vocational competency learning difficulties of Vocational High School students, and (b) determine the performance of the diagnostic test system. This study was the second year of a three year research plan. This research was a Software Research and Development. The development model used in this study was a modification of linear sequential model or known as life cycle or the classic waterfall model with 4 steps. Step 1, analysis of system requirements and system design, was done in the first year. Step 2, system implementation and validation, was conducted in the second year. The validation of the system was done by involving 35 teachers who were asked to complete a questionnaire to see performance, design, and adaptability of the system. The data were analyzed by using descriptive statistics. Step 3, the evaluation system utilization, will be held in the third year. The diagnostic test system of basic vocational competency learning difficulties of Vocational High School students has been developed using web client-server architecture, three programming languages (PHP, HTML, and Java), Apache web server, MySQL, and Chrome web browser. The system has three user groups, namely administrators, teachers, and students. The performance, design, and adaptability of the system as a whole have verage score of 3.57 on scale of 1 to 4 and categorized as a very good system. That is why the system can be used in further studies in the third year, i.e. evaluation of system utilization.

Keywords: basic vocational competencies, diagnostic test 



\section{Pendahuluan}

Diagnostik kesulitan belajar perlu dilakukan oleh guru jika guru ingin siswanya dapat mencapai kriteria ketuntasan minimal (KKM) secara efisien melalui program pembelajaran remidi yang tepat sasaran. Masalahnya adalah selama ini belum ada panduan dan alat yang memudahkan guru melakukan diagnostik kesulitan belajar siswa.

Depdiknas (2007, pp.5-7) misalnya, memberikan panduan berupa tujuh langkah diagnosis kesulitan belajar dengan urut-urutannya sulit diikuti. Langkah tersebut mencakup: (1) mengidentifikasi kompetensi dasar yang belum tercapai ketuntasannya, (2) menentukan kemungkinan sumber masalah, (3) menentukan bentuk dan jumlah soal yang sesuai, (4) menyusun kisi-kisi soal, (5) menulis soal, (6) mereviu soal, dan (7) menyusun kriteria penilaian.

Langkah pertama, mengidentifikasi kompetensi dasar yang belum tercapai ketuntasannya, membuat guru bingung. Hal ini disebabkan guru belum melakukan tes tetapi sudah diminta untuk mengidentifikasi kompetensi dasar yang belum dicapai ketuntasannya oleh siswa. Karena itu guru SMK jarang melakukan diagnostik kesulitan belajar Kompetensi Dasar Kejuruan. Padahal kompetensi tersebut merupakan materi yang diujikan secara nasional dan menjadi dasar pengetahuan yang harus dikuasai siswa agar dapat menguasai Kompetensi Kejuruan yang dipilih.

Rajeswari (2004, pp.45-45) menyatakan ada lima tahap dalam menyiapkan tes diagnostik. Langkah tersebut adalah merencanakan, menulis butir soal, merakit soal, membuat petunjuk dan rencana penilaian, dan mereview soal. Jika disimak, tahap penyiapan tes diagnostik yang dikemukakan oleh Rajeswari tersebut tidak berbeda dengan tahap penyiapan tes biasa. Perbedaan tes diagnostik atau bukan tes diagnostik terutama dibedakan pada tujuan pelaksanaan tes.

Karena tidak adanya langkah-langkah sistematis yang harus diikuti guru dalam melaksanakan tes diagnostik, peneliti menganggap perlu mengembangkan sistem tes diag- nostik yang mudah digunakan oleh guru dan siswa. Sistem ini diharapkan dapat menunjukkan kesulitan belajar setiap siswa pada Kompetensi Dasar Kejuruan. Dengan diketahui kesulitan belajar setiap siswa pada Kompetensi Dasar Kejuruan, maka guru dapat melakukan pembelajaran remidi kepada setiap siswa secara tepat, sehingga semua siswa dapat menguasai kompetensi dasar kejuruan secara menyeluruh.

Penelitian ini merupakan penelitian tahun jamak. Tujuan penelitian ini adalah: (a) mengetahui sistem tes diagnostik diagnostik kesulitan belajar Kompetensi Dasar Kejuruan yang baik menurut guru, (b) mengembangkan sistem tes diagnostik diagnostik kesulitan belajar Kompetensi Dasar Kejuruan sesuai masukan guru, (c) mengetahui kinerja sistem tes diagnostik diagnostik kesulitan belajar Kompetensi Dasar Kejuruan yang dikembangkan, dan (d) mengetahui dampak penerapan sistem tes diagnostik diagnostik kesulitan belajar Kompetensi Dasar Kejuruan di sekolah.

Tujuan penelitian pertama telah terjawab pada penelitian tahun pertama. Tujuan penelitian kedua dan ketiga dijawab pada pelaksanaan penelitian tahun kedua, sedangkan tujuan penelitian yang terakhir akan dijawab melalui penelitian tahun ketiga.

Kata diagnostik banyak digunakan dalam dunia kedokteran, psikologi, dan pendidikan. Rupp, et al., (2010, p.1) menyatakan diagnostik berarti usaha untuk mengetahui secara tepat (to know precisely), untuk memutuskan (to decide), dan untuk sependapat (to agree upon). Rajeswari (2004, p.36) menyatakan tes diagnostik adalah tes yang digunakan untuk mendiagnosa kelemahan dan kekuatan siswa pada pelajaran tertentu. Zhongbao Zhao (2013, p.43) menyatakan tes diagnostik utamanya adalah untuk mengetahui kekuatan dan kelemahan siswa dan memberi masukan kepada guru dan siswa untuk membuat keputusan terkait dengan perbaikan proses mengajar dan proses belajar.

Berdasarkan tiga pendapat tersebut dapat disimpulkan bahwa tes diagnostik adalah tes yang dapat digunakan untuk me- 
ngetahui secara tepat dan memastikan kelemahan dan kekuatan siswa pada pelajaran tertentu. Bagi guru informasi yang diperoleh dari tes diagnostik dapat digunakan untuk memperbaiki proses pembelajaran, sedangkan bagi siswa dapat digunakan untuk memperbaiki proses belajar. Jadi, informasi dari tes diagnostik dapat dimanfaatkan guru dan siswa dalam program pembelajaran remedial.

Depdiknas (2007, p.2) memaknai tes diagnostik sebagai tes yang dapat digunakan untuk mengetahui kelemahan dan kekuatan siswa. Dengan demikian, hasil tes diagnostik dapat digunakan sebagai dasar memberikan tindak lanjut berupa perlakuan yang tepat dan sesuai dengan kelemahan yang dimiliki siswa. Tes diagnostik memiliki dua fungsi utama, yaitu: mengidentifikasi masalah atau kesalahan yang dialami siswa dan merencanakan tindak lanjut berupa upaya-upaya pemecahan sesuai masalah atau kesalahan yang telah teridentifikasi.

Hasil tes diagnostik dapat digunakan untuk melakukan intervensi yang efektif kepada siswa secara individual atau klasikal, dalam upaya mengevaluasi proses pembelajaran. Tes diagnostik tidak hanya memberikan informasi berupa angka sebagai indikator kemampuan siswa, namun juga mendeskripsikan penguasaan siswa pada sub kemampuan tertentu.

Rajeswari (2004, p.46) menyatakan enam kondisi yang harus diperhatikan dalam pelaksanaan tes diagnostik. Keenam kondisi tersebut adalah: (1) dilakukan meningkatkan prestasi siswa bukan untuk menentukan kelulusan, (2) dilaksanakan dalam suasana yang nyaman dan menyenangkan, (3) dikerjakan dengan jujur oleh siswa secara mandiri, (4) dalam tes diagnostik siswa dapat menanyakan hal-hal yang tidak jelas, (5) guru mendorong siswa untuk mengerjakan semua soal, dan (6) jadwal pelaksanaan tidak ketat atau siswa dapat mengambil tes sesuai dengan waktu yang dimiliki.

Alderson (2005, p.11) menyatakan tes diagnostik seharusnya memiliki enam sifat sebagai berikut: (1) dapat menampilkan indikator kompetensi yang telah atau belum dikuasai siswa; (2) indikator kompetensi yang belum dikuasai siswa ditunjukkan dengan jelas pada hasil tes diagnostik; (3) hasil tes diagnostik dapat mengarahkan siswa untuk mempelajari indikator kompetensi yang masih perlu dipelajari kembali; (4) hasil tes diagnostik dapat langsung ditindaklanjuti siswa untuk memperbaiki pencapaian kompetensi; (5) hasil tes diagnostik langsung dapat diketahui siswa setelah siswa selesai melaksanakan tes, dan 6) soal-soal yang ada dalam tes diagnostik dapat mengukur pencapaian kompetensi siswa secara mendalam.

Uraian tersebut menunjukkan bahwa tes diagnostik yang efektif harus terintegrasi dengan baik dalam kegiatan belajar mengajar. Tes diagnostik harus dapat membantu guru memahami kesulitan siswa dalam menyelesaikan soal yang terkait dengan kompetensi yang harus dikuasai siswa. Dengan demikian, skor yang diperoleh dari tes diagnostik harus dipandang sebagai informasi tentang kelemahan siswa yang harus digunakan perbaikan proses belajar mengajar agar siswa dapat mencapai ketuntasan minimal.

Agar hasil tes diagnostik langsung dapat diketahui siswa setelah siswa selesai melaksanakan tes sebagaimana dikemukakan oleh Alderson (2005, p.11), guru harus segera mengoreksi hasil tes diagnostik siswa. Jika jumlah siswa banyak hal ini sangat memberatkan guru. Oleh karena itu, tes diagnostik yang dikembangkan dalam bentuk program komputer akan sangat memudahkan guru.

McCall, dkk. (1977, pp.2-3) dan Bowen, dkk. (1985, pp.2-17) menyatakan pengembangan program komputer harus mempertimbangkan aspek kinerja, rancangan, dan adaptabilitas program. Kinerja program diketahui dari efisiensi, integritas, reliabilitas, survivabilitas, dan usabilitas program. Rancangan program dapat dinilai dari kebenaran, kemudahan untuk diperbaiki, dan kemudahan untuk diuji. Adaptabilitas program ditandai dengan kemampuan dikembangkan lebih lanjut (expandability), fleksibilitas, interoperabilitas, portabilitas, dan kemampuan untuk digunakan kembali (reusability) dari program tersebut. 


\section{Metode Penelitian}

Hasil penelitian ini merupakan hasil penelitian tahun pertama dari tiga tahun yang direncanakan. Penelitian ini menggunakan pendekatan penelitian Research and Development perangkat lunak. Model pengembangan yang digunakan dalam penelitian ini adalah model modifikasi linear sequential yang disebut juga sebagai classic life cycle atau model waterfall yang memiliki 4 langkah, yaitu analisis, desain, implementasi, dan evaluasi (Sharma, 2012).

Penelitian tahun pertama meliputi kegiatan: menganalisis kebutuhan dan merancang sistem. Analisis kebutuhan, untuk mengidentifikasi kebutuhan guru SMK akan sistem yang diharapkan dapat digunakan untuk mengidentifikasi kesulitan belajar siswa SMK pada mata pelajaran Kompetensi Dasar Kejuruan dari berbagai Bidang Keahlian. Kegiatan ini dilakukan melalui Focus Discussion Group (FGD) yang melibatkan 25 guru SMK di Daerah Istimewa Yogyakarta dan 5 dosen yang memahami SMK dan aplikasi komputer. Data hasil FGD kemudian digunakan untuk merancang tampilan program, mekanisme kerja program, dan algoritma programan.

Penelitian tahun kedua adalah mengimplementasikan rancangan hasil penelitian tahun pertama menjadi program komputer dan validasi program. Sistem yang dikembangkan dalam penelitian ini adalah menggunakan arsitektur client-server berbasis web. Bahasa pemrograman yang digunakan dalam penelitian ini adalah PHP, HTML, dan Java. Perangkat lunak pendukung adalah web server Apache, MySQL, dan web browser Chrome yang dijalankan pada komputer dengan sistem operasi Windows.

Validasi sistem melibatkan 35 guru SMK yang sudah terbiasa meng-gunakan komputer untuk keperluan administrasi dan pembelajaran. Cakupan validasi mengikuti pendapat McCall dkk. (1977, pp.2-3) dan Bowen, dkk. (1985, pp.2-17) yaitu meliputi aspek kinerja, rancangan, dan adaptabilitas program. Instrumen validasi sistem dibuat dalam bentuk angket skala Likert dengan rentang penilaian antara 1 sampai dengan 4 .
Kisi-kisi instrumen validasi sistem ditunjukkan pada Tabel 1. Hasil anlisis data validasi membuktikan bahwa instrumen penelitian valid dan reliabel. Hal ini ditunjukkan dengan daya beda semua butir yang ada $\geq$ 0,3 dan koefisien alfa $=0,735$. Analisis data validasi sistem dilakukan dengan statistik deskriptif.

Tabel 1. Kisi-kisi Instrumen Validasi Sistem Tes Diagnostik

\begin{tabular}{llcl}
\hline $\begin{array}{l}\text { No Aspek yang } \\
\text { Dinilai }\end{array}$ & Indikator & $\begin{array}{c}\text { Jumlah } \\
\text { Butir }\end{array}$ & $\begin{array}{c}\text { Nomor } \\
\text { Butir }\end{array}$ \\
\hline 1. Kinerja & Efisiensi & 2 & 1,2 \\
& Integritas & 2 & 3,4 \\
& Reliabilitas & 4 & $5,6,7,8$ \\
& Survivabilitas & 1 & 9 \\
& Usabilitas & 3 & $10,11,12$ \\
\hline 2. Rancangan & Kebenaran & 2 & 13,14 \\
& Kemudahan & 1 & 15 \\
& diperbaiki & & \\
& Kemudahan & 1 & 16 \\
& diuji & & \\
\hline 3. Adaptabilitas & Ekspandabilitas & 2 & 17,18 \\
& Flexibilitas & 1 & 19 \\
& Interoperabilitas & 1 & 20 \\
& Portabilitas & 2 & 21,22 \\
& Reusabilitas & 1 & 23 \\
\hline
\end{tabular}

\section{Hasil dan Pembahasan}

Sesuai hasil FGD tahun pertama, sistem dibuat untuk tiga kelompok pengguna, yaitu admin, guru, dan siswa. Admin memiliki kewenangan mengelola sistem dan semua data. Guru memiliki kewenangan mengembangkan soal, mengatur pelaksanaan tes diagnostik, menentukan siswa yang dapat mengikuti tes, dan melihat hasil tes siswa. Siswa memiliki kewenangan yang paling terbatas, yaitu hanya dapat mengikuti tes sesuai dengan mata pelajaran yang mereka ikuti dan melihat hasil tes. Sebagai sistem client-server dengan kewenangan pengguna yang berbeda-beda, sistem ini menggunakan halaman login untuk mengidentifikasi pengguna. 
Setelah memasukkan Username dan Password dengan benar, maka pengguna akan ditunjukkan menu yang tersedia sesuai dengan kewenangannnya. Gambar 1 menunjukkan menu untuk admin. Gambar 2 adalah tampilan untuk guru, sedangkan Gambar 3 merupakan tampilan jika seseorang login sebagai siswa.

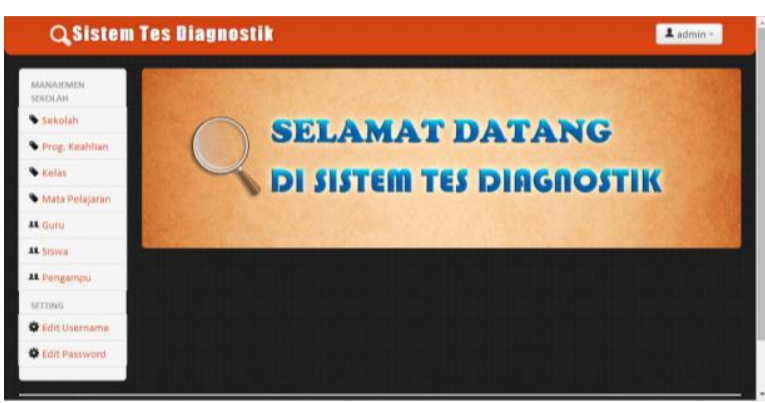

Gambar 1. Menu untuk Admin

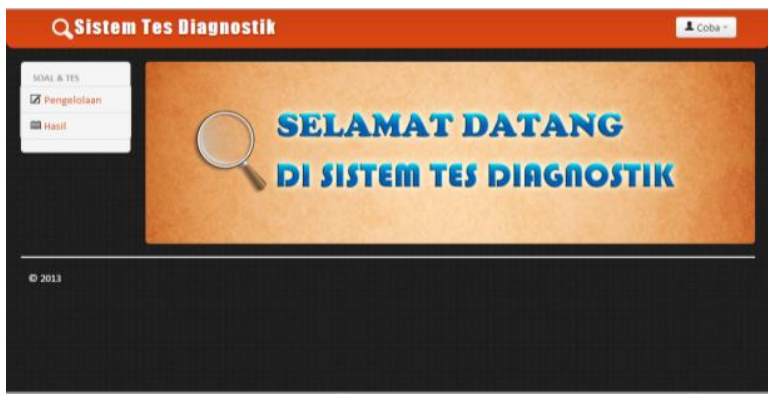

Gambar 2. Menu untuk Guru



Gambar 3. Menu untuk Siswa

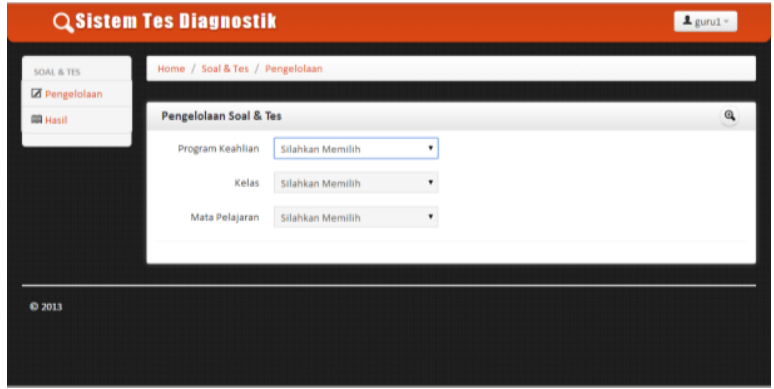

Gambar 4. Submenu untuk Guru

Gambar 1 sampai dengan Gambar 3 memunjukkan bahwa menu untuk setiap pengguna berbeda-beda tergantung dari pengguna sistem tersebut. Menu admin adalah yang banyak. Menu untuk guru terlihat cukup sedikit. Akan tetapi, jika menu tersebut diklik, maka akan muncul submenu. Gambar 4 merupakan contoh submenu untuk guru.

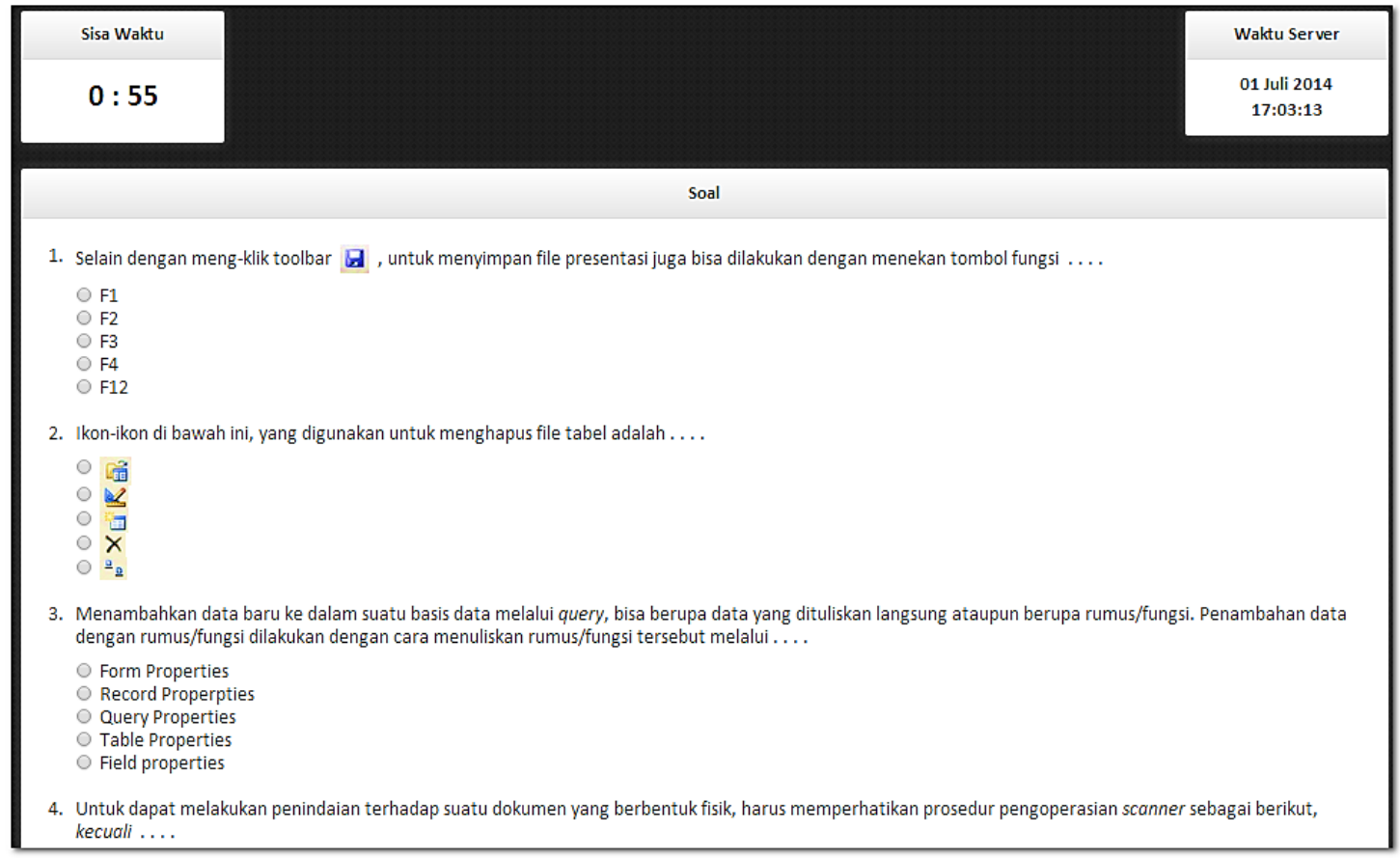

Gambar 5. Tampilan Tes untuk Siswa 
Menu siswa adalah yang paling sedikit. Setelah login, siswa dapat memilih tes yang akan diikuti. Gambar 5 merupakan contoh tampilan tes untuk siswa, sedangkan Gambar 6 merupakan tampilan hasil tes siswa.

Gambar 6 menunjukkan bahwa KKM (Kriteria Ketuntasan Minimal) mata pelajaran yang diujikan adalah 70 atau $70 \%$. Gambar 6 juga menunjukkan bahwa persen jawaban benar pada semua indikator yang diujikan adalah $0 \%$ yang berarti lebih kecil dari KKM mata pelajaran. Capaian indikator yang lebih kecil dari KKM akan ditampilkan dengan warna merah supaya mendapat perhatian siswa dan guru.

LAPORAN HASIL TES

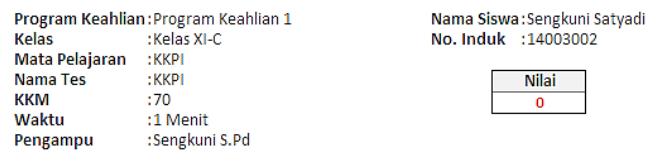

\begin{tabular}{|c|l|c|c|c|c|}
\hline No & \multicolumn{1}{|c|}{ Indikator } & $\begin{array}{c}\text { Jumlah } \\
\text { Soal }\end{array}$ & $\begin{array}{c}\text { Jumlah } \\
\text { Benar }\end{array}$ & $\begin{array}{c}\% \\
\text { Benar } \\
\text { Indikator }\end{array}$ & $\begin{array}{c}\% \\
\text { Benar } \\
\text { Total }\end{array}$ \\
\hline 1 & $\begin{array}{l}\text { Menjalankan file presentasi melalui menubar atau } \\
\text { menekan tombol F5 }\end{array}$ & 2 & 0 & $0 \%$ & $0 \%$ \\
\hline 2 & $\begin{array}{l}\text { Mengenal menubar dan toolbar beserta fungsinya pada } \\
\text { perangkat lunak presentasi }\end{array}$ & 2 & 0 & $0 \%$ & $0 \%$ \\
\hline & $\begin{array}{l}\text { Menjalankan perintah-perintah editing sederhana, } \\
\text { seperti: mengetik huruf/kata/ kalimat, memformat } \\
\text { hurufffont, mengatur text alignment, menggunakan } \\
\text { bullet and numbering, membuat header and footer dan } \\
\text { page numbering, menambahkan/menyisipkan slide, } \\
\text { memasukkan gambar/picture, diagram, text box, movie } \\
\text { and sound, chart, object, membuat tabel, dan mengatur } \\
\text { background }\end{array}$ & 1 & 0 & $0 \%$ & $0 \%$ \\
\hline 4 & $\begin{array}{l}\text { Menjalankan perintah pengaturan slide, seperti: slide } \\
\text { layout, slide design, color schemes, costum animation dan } \\
\text { slide transition }\end{array}$ & 1 & 0 & $0 \%$ & $0 \%$ \\
\hline
\end{tabular}

Gambar 6. Tampilan Hasil Tes untuk Siswa

Validasi sistem dimaksudkan untuk mengetahui kualitas sistem. Dalam penelitian ini kualitas sistem dilihat dari rata-rata penilaian aspek dan indikatornya. Rangkuman penilaian aspek dan indikator kualitas sistem berdasarkan pernyataan tertutup yang ada dalam angket memperoleh hasil seperti ditunjukkan pada Gambar 7, Gambar 8, dan Gambar 9.

Gambar 7 menunjukkan bahwa indikator kinerja sistem yang rata-rata penilaiannya paling rendah adalah efisiensi $(3,21)$ dan yang paling tinggi adalah survivabilitas $(3,87)$. Efisiensi menilai apakah sistem dapat dijalankan pada komputer dengan spesifi- kasi hardware dan software yang berbedabeda tanpa perlu mengubah kode program, sedangkan survivabilitas menilai apakah sistem tetap berfungsi meskipun diakses oleh banyak pengguna.

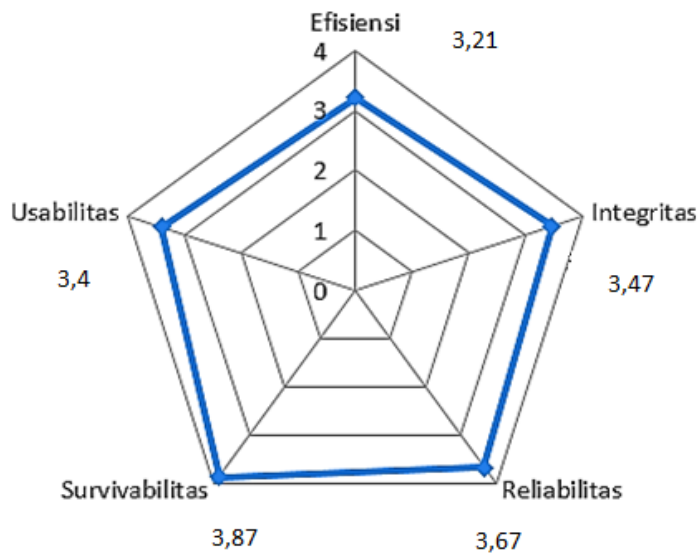

Gambar 7. Diagram Radar Kinerja Sistem

Jika dihitung berdasarkan angka-angka yang ada di Gambar 7, rata-rata penilaian aspek kinerja sistem adalah 3.524 dari skala $1-4$. Jika $1 / 4$ bagian pertama skala dikategorikan tidak baik, $1 / 4$ bagian kedua dikategorikan kurang baik, $1 / 4$ bagian ketiga dikategorikan baik, dan 1/4 bagian keempat dikategorikan sangat baik; maka penilaian validator terhadap kinerja sistem termasuk kategori sangat baik.

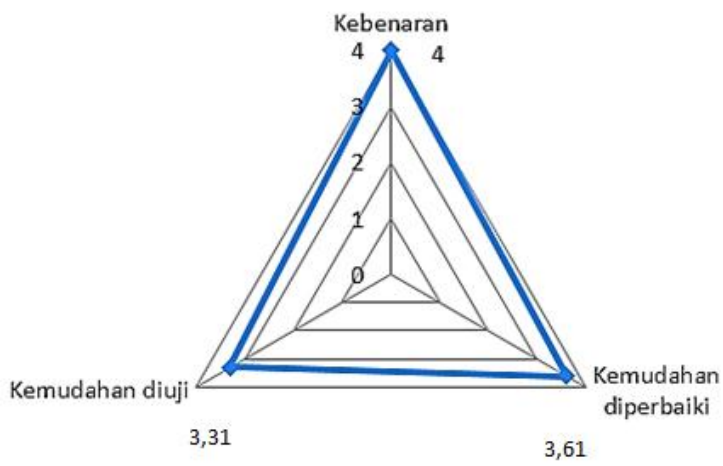

Gambar 8. Diagram Radar Rancangan Sistem

Gambar 8 menunjukkan bahwa indikator rancangan sistem yang rata-rata penilaiannya paling rendah adalah kemudahan untuk diuji (3.31) dan yang paling tinggi adalah kebenaran (4.0). Kemudahan untuk diuji menilai apakah pengguna dapat men- 
coba fungsi sistem dengan mudah, sedangkan kebenaran menilai apakah sistem dapat membantu tugas guru melakukan tes diagnostik dan apakah sistem dapat membantu siswa mengetahui kesulitan belajar yang dialami.

Berdasarkan angka-angka yang ada pada Gambar 8 diperoleh rata-rata penilaian aspek rancangan sistem 3.64 dari skala 1 4. Jika digunakan kategorisasi yang sama dengan yang digunakan pada aspek kinerja sistem, maka penilaian validator terhadap rancangan sistem termasuk kategori sangat baik.

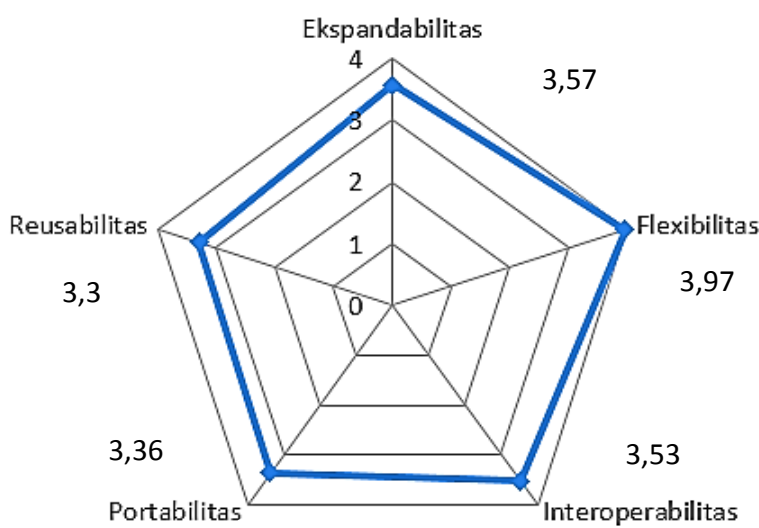

\section{Gambar 9. Diagram Radar Adaptabilitas Sistem}

Gambar 9 menunjukkan bahwa indikator adaptabilitas sistem yang rata-rata penilaiannya paling rendah adalah reuseabilitas (3.3) dan yang paling tinggi adalah flexibilitas (3.97). Reuseabilitas menilai apakah output sistem dapat disimpan dalam bentuk file yang dapat dibuka dengan program komputer yang relevan, sedangkan flexibilitas menilai apakah sistem dapat akses dengan berbagai web browser tanpa masalah. Menggunakan angka-angka yang ada paga Gambar 9 diperoleh rata-rata penilaian aspek adaptabilitas sistem 3,546 dari skala $1-4$. Jika digunakan kategorisasi yang sama dengan aspek kinerja sistem, maka penilaian validator terhadap adaptabilitas sistem termasuk kategori sangat baik. Jika digunakan kategorisasi yang sama dengan aspek kinerja sistem, maka penilaian validator terhadap adaptabilitas sistem termasuk kategori sangat baik.
Terhadap pertanyaan terbuka yang meminta masukan terhadap sistem yang telah dikembangkan, ternyata tidak semua validator memberi masukan. Beberapa masukan yang ada adalah sistem sudah bagus dan perlu pelatihan serta sosialisasi bagi calon pengguna di tingkat sekolah. Hal ini sejalan dengan data kuantitatif yang menunjukkan bahwa aspek kinerja, rancangan, dan adaptabilitas sistem rata-rata penilainnya cukup tinggi.

Secara keseluruhan, kualitas sistem yang ditandai aspek kinerja, rancangan, dan adaptabilitas sistem (McCall dkk., 1977, pp.2-3 dan Bowen, dkk., 1985, pp.2-17) mempunyai rata-rata penilaian sebesar 3.57 dari skala 1 - 4. Jika digunakan kategorisasi yang sama dengan yang digunakan sebelumnya, maka penilaian validator terhadap kualitas sistem termasuk kategori sangat baik. Karena itu dapat digunakan pada penelitian tahun ketiga.

\section{Simpulan}

Sistem tes diagnostik kesulitan belajar kompetensi dasar kejuruan siswa SMK dengan arsitektur web client-server dapat dikembahangkan dengan bahasa pemrograman PHP, HTML, dan Java dengan perangkat lunak pendukungnya adalah web server Apache, MySQL, dan web browser Chrome. Sistem ini memiliki tiga kelompok pengguna, yaitu admin, guru, dan siswa. Admin memiliki kewenangan paling banyak, guru memiliki kewenangan mengembangkan soal, mengatur pelaksanaan tes diagnostik, menentukan siswa yang dapat mengikuti tes, dan melihat hasil tes siswa. Siswa memiliki kewenangan yang paling terbatas, yaitu hanya dapat mengikuti tes sesuai dengan mata pelajaran yang mereka ikuti dan melihat hasil tes.

Secara keseluruhan, kualitas sistem yang ditandai aspek kinerja, rancangan, dan adaptabilitas mempunyai rata-rata penilaian sebesar 3,57 dan termasuk kategori sangat baik. Oleh, karena itu sistem dapat digunakan pada penelitian lebih lanjut pada tahun ketiga. 


\section{Daftar Pustaka}

Alderson, J. C. (2005). Diagnosing Foreign Language Proficiency: The Interface between Learning and Assessment. London: Continuum.

Bowen, T.P., Wigle, G.B., and Tsai, J.T. 1985. Specification of Software Quality Attributes Software Quality Evaluation Guidebook. New York: Rome Air Development Center.

Depdiknas (2007). Tes diagnostik, Direktorat Pembinaan Sekolah Menengah Pertama, Direktorat Jenderal Manajemen Pendidikan Dasar dan Menengah.

McCall, J.A., Richards, P.K., and Walters, G.F. 1977. Factors in Software Quality Preliminary Handbook on Software Quality for an Acquisition Manager. New York: Rome Air Development Center.

Rajeswari. (2004). Preparation and Testing of Remedial Teaching Materials for
Educationally Backward Students in Chemistry at The Secondary School Level. Kottayam: School of Pedagogical Sciences Mahatma Gandhi University.

Rupp, A.A., Templin, J. \& Henson, R.A. (2010). Diagnostic measurement: Theory, methods and applications. New York: The Guilford Press.

Sharma, G. (2012). Software engineering notes. Diambil pada tanggal 20 November 2012 dari http://guideforengineers.com/wordp ress/wpcontent/uploads/2009/10/se notes. pdf

Zhongbao Zhao. (2013). An Overview of Studies on Diagnostic Testing and its Implications for the Development of Diagnostic Speaking Test. International Journal of English Linguistics. Vol. 3 No. 1, $41-45$. 